\title{
Intermodal Transportation Safety and Security Issues: Training against Terrorism
}

\author{
Ronald W. Tarr, Vicki McGurk, and Carol Jones \\ University of Central Florida
}

\begin{abstract}
Since $9 / 11$, our world has changed. The threats now facing us are extreme and unpredictable. The potential for terrorists to use public transit to deliver bombs or turn public transit vehicles into bombs underscores the importance of training-training that can help us prepare to deal with the advent of terrorism on a devastating scale. This paper explains how training in teamwork and decision-making aided the reaction of mass transit agencies during the 9/11 attacks. It also describes the new techniques and technologies that can be used to provide even better training for future attacks.
\end{abstract}

\section{Introduction}

Jennifer Dorn, Federal Transit Administrator, highlighted the risks facing mass transit when she said:

The State Department reports that in 1991, 20 percent of all violent attacks worldwide were against transportation targets; by 1998, 40 percent involved transportation targets, with a growing number directed at bus and rail systems. The recent attacks on the World Trade Center ... reminds us all that we must 
respond to a new terrorist reality-terrorism that is well-financed, well-organized and ruthless. The credible threat of increasing terrorism directed toward our nation's transit systems requires that we take immediate prudent action to prevent, prepare for and respond to violence-the nature and magnitude of which was once unimaginable (APTA 2001).

Intermodal transportation systems can be defined as any transport of people or freight on our soil, we must consider countless ways to prepare for more attacks and lay out plans to avert another tragedy. This article will focus on the types of threats from terrorists our intermodal transit systems face (Figure 1.).

\section{Figure 1. Terrorist attacks against transportation by world region, 1998}

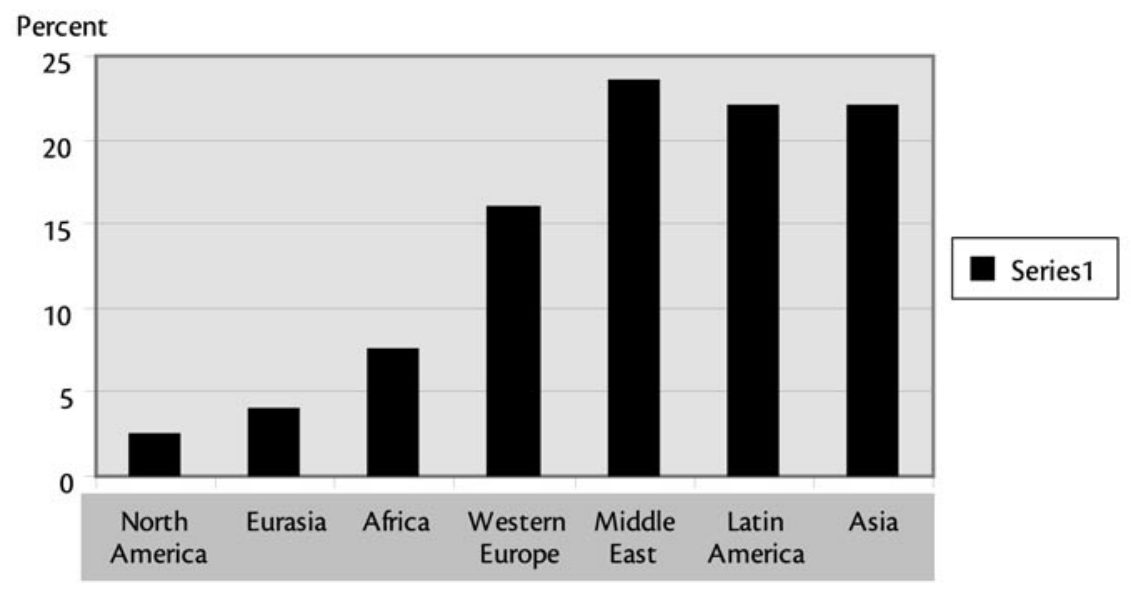

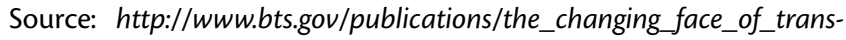
portation/html/figure_07_09.html

The article is organized into three broad areas:

1. Current situation regarding security and terrorism for intermodal transit

- Response of mass transit agencies on 9/11

- Types of terrorist threats facing intermodal transit facilities and intermodal transportation systems 
2. Current solutions

- Increased tracking and inspection of certain shipments

- Employee training

- Inspection of priority tracks, tunnels and bridges

- Increasing security for school buses, trucks, subways and trains

3. Future solutions proposed by University of Central Florida's Center for Advanced Transportation Systems Simulation (UCF-CATSS), using research and an advanced application approach to security

- Awareness education and training

- New performance technologies to provide the critical response to terrorist attacks and also to avoid or defuse threats

\section{Current Situation Regarding Terrorist Security for Intermodal Transit}

\section{The Response of Mass Transit Agencies on 9/11}

In the aftermath of 9/11, virtually every mass transit system around Ground Zero was prepared to help. Many systems provided free transportation, created detours, accepted each other's riders, and took food and blankets to victims. All in all, the outpouring of sympathy and generosity was astounding, and the ability to reroute lines and get people home showed remarkable training. The response by the mass transit systems demonstrated that many transit agencies could respond to emergencies, make quick decisions, and come up with creative solutions because they were prepared.

"America Under Threat: Transit Responds to Terrorism" was a special report describing how mass transit agencies in cities all over the United States responded to the terrorist attacks of $9 / 11$. In each city's section of the report, similar actions were taken - transit employees made quick decisions and depended on teamwork to help reroute riders and lines so that people could be evacuated from Ground Zero. When the Federal Aviation Commission closed airports, this rerouting included transit personnel finding transportation for passengers stranded at airports, as well as setting up lodging for them. In Austin, Texas, armed police in full uniform drove the mass transit buses transporting these stranded travelers (APTA 2001). 
Mass transit agencies in cities all over the nation have had to reconsider safety and security procedures in the face of terrorism. This has caused a rise in requests for new security devices, such as:

- electronic employee ID targets and vehicular gates at all metro facility entrance points;

- metro-rail fiber optic network, vital for video recording devices;

- programmable intrusion equipment to alert police of the location of any unauthorized intrusion into the subway system;

- closed-circuit TV and motion detection alarms for metro-rail yard perimeter fencing and shop facilities;

- personal protection equipment, training and satellite telephones for employees;

- expansion of the chemical emergency sensor program;

- bomb-resistant containers at all metro-rail stations; and

- high-visibility uniformed patrols at vulnerable stations with additional K-9 teams and vehicles for explosive detection.

\section{Figure 2. Closed Circuit TV (CCTV) camera}

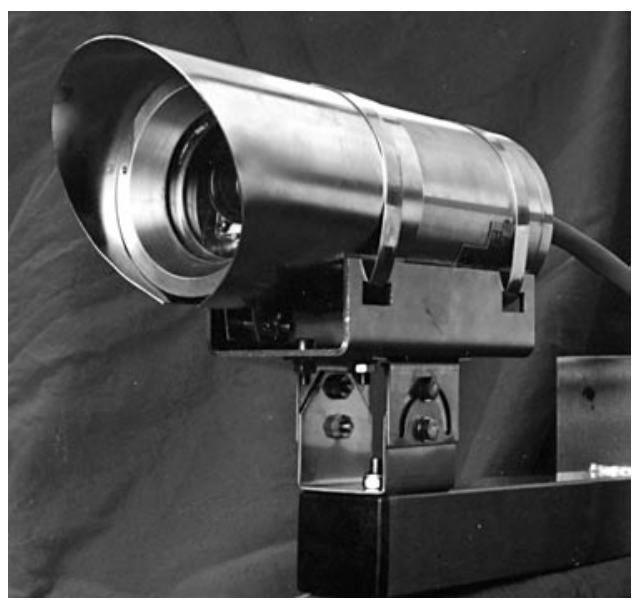

Source: Fugro OCEANOR, http://www. oceanor.no/ products/cctv 
Security devices are critical to protect passengers from terrorist attacks. They are also critical to keep our public transportation vehicles from being used as weapons. Norman Mineta, the U.S. Transportation Secretary, speaking at a national transportation security summit, stated that U.S. transportation systems are "at risk of being targets of terrorists. They are also at risk of being used as weapons against Americans-weapons delivery systems used to damage or destroy our communities" (APTA 2001).

Because of $9 / 11$, many transit agencies have decided to strengthen their current protocols, while also developing and implementing new internal policies and procedures. In-house security work groups have been formed; staff members are participating in seminars on terrorism, bioterrorism, anthrax and other security and safety measures.

Atlanta and San Francisco transit agencies were able to respond quickly to handle stranded passengers and create new routes because of previous training. The Atlanta police had participated in several training programs in preparation for the 1996 Olympic Games (APTA 2001). Training included sending special teams to biological and chemical response classes offered by the U.S. Army. Atlanta also has a bomb team equipped with a computerized robot and K-9 units.

\section{Figure 3. K-9 unit training}

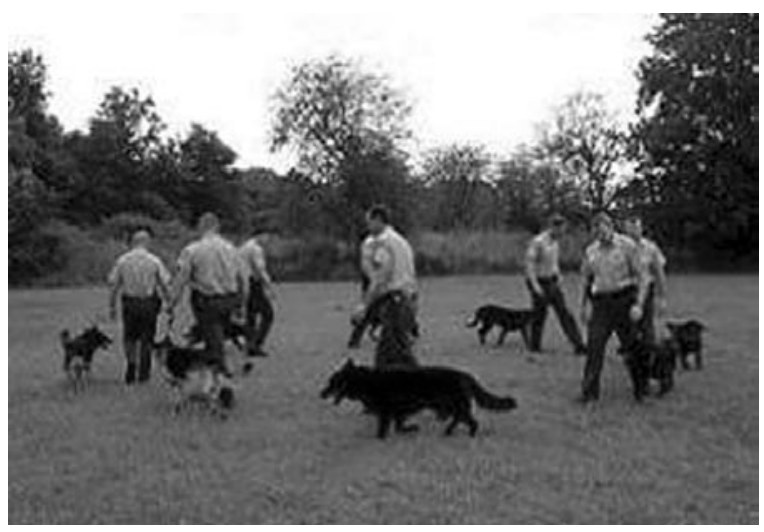

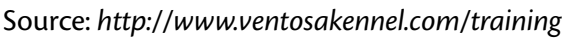


The San Francisco Bay Area Rapid Transit (BART) also was prepared because of its experience with counterterrorism efforts. BART has been involved in local, regional and national planning for counterterrorism since the Gulf War (APTA 2001). BART hosted a federally sponsored counterterrorism forum in 1997. Since the subway attack in Tokyo in 1995, BART police, station agents and other key personnel have received specialized training.

Other cities have participated in training seminars or sent employees for training. In Cleveland, the Regional Transit Authority (RTA) hosted an FBI terrorist and operational response training seminar that outlined tactics related to incidents using explosives or chemical, biological, or nuclear devices.

In addition to the seminars and off-site training that some cities have had, drills have provided effective training. A drill in Miami-Dade County (Florida) showed the transit authorities how easily anyone in a recognizable uniform, even those without badges, could get into their facilities. This provoked new training to help employees learn how to challenge people who have no identification. In addition, Miami-Dade has changed access to secure areas, moving from keypad to a proximity card in conjunction with a personal code.

Our mass transit agencies did a highly commendable job in employing their decision-making and teamwork skills to help in a time of great crisis. Now that our transit systems have shown that they can react to terrorist attacks, we need to help them acquire the security devices and training they need to be proactive in preventing another tragedy.

\section{Types of Terrorist Threats Facing Intermodal Transit}

Trains. Railroad freight and passengers are extremely vulnerable to terrorist attacks. Between 1998 and 2003, there were approximately 181 attacks worldwide on trains and related rail targets such as depots, ticket stations and rail bridges. Attacks on light rail systems and subway systems are included in this estimate. These attacks resulted in 431 deaths and several thousand injuries (Riley 2004).

In the aftermath of 9/11, the Association of American Railroads (AAR) and the Transportation Security Administration (TSA) have worked together to ensure the safety of the railroad system by increasing:

- security of information systems and property;

- tracking and inspection of certain shipments;

- employee training; and 
- inspection of priority tracks, tunnels and bridges.

One of the areas of greatest concern since the terrorist attacks is the security of the rail industry's information systems network. On March 23, 2004, before the Senate Commerce Committee Hearing on Transportation Security, Edward Hamberger, President and Chief Executive Officer of the AAR, stated: "The industry significantly increased cyber-security procedures and techniques. Employee records were compared with FBI terrorist lists. Security briefings, like safety briefings, became a daily part of many employees' jobs" (Hamberger 2004).

According to the U.S. Department of Transportation, freight railroads have a large physical infrastructure and are heavily dependent on information technology in their daily operations (Mosely 2002). These types of systems are vulnerable to terrorist or hacker activity intended to bring about one of three scenarios.

1. Denial of service-terrorists make a direct attack on an information system that results in a disruption of service among a number of unprotected computers on the Internet.

2. Hazardous material control-terrorists gain control of hazardous materials by cyber attack and cause an accident, resulting in the release of hazardous materials.

3. Weapons of mass destruction shipment-terrorists gain access to sensitive freight information systems in order to move weapons around the country.

Subways. The first attack on a subway system using weapons of mass destruction took place in 1995 when the Japanese doomsday cult Aum Shinrikyo released sarin gas into the Tokyo subway system, killing 12 people and sending more than 5,000 to the hospital. Since $9 / 11$, there have been numerous general warnings of possible terrorist attacks on parts of the ground transportation system, including subways. Unlike airlines, which have several security checkpoints that screen passengers and luggage, subways are designed to be easily accessible and are therefore harder to protect (Council on Foreign Relations 2004).

The physical design of a subway system - enclosed spaces packed with people during specific times of the day-makes it a tempting target for terrorists. Biological or chemical attacks in a subway would have devastating results. This is because air currents above ground, as well as those generated by the movement of trains through the tunnels, could spread germs or gases throughout a subway station 
and through ventilation systems to the streets above, leading to the infection of large numbers of people (Council on Foreign Relations 2004).

Trucks. According to Gary Petty, president of the National Private Truck Council (NPTC), the threat of terrorists using trucks as weapons in the United States is high, largely because trucks have become the weapon of choice for terrorists. Petty says, "There have been 150 terrorist attacks worldwide over the last 10 years using trucks_trucks are the modality of choice for terrorists" (Kilcarr 2003).

A large percentage of trucks carry hazardous freight that would provide terrorists with a weapon that could be exploded on impact or detonation. Each day, gasoline tanker trucks across the United States make about 50,000 trips. Another segment of the trucking fleet hauls other dangerous materials, such as chlorine, that could be deliberately released. These trucks often are left unattended at refueling depots with their engines running, or they deliver their loads to deserted, unprotected areas (Wilen 2003).

Buses. Buses remain a favorite target for terrorists. According to the FBI, between 1920 and 2000, nearly 40 percent of mass transit targets internationally were buses, including school buses. Why would terrorists target school buses? Because, basically, they are easy targets - they have predictable routes and are highly visible. In addition, although schoolchildren pose no threat to terrorists, by hijacking a bus full of children, terrorists can "crush the heart" of a nation (Paul 2004a). Because school buses are easy targets, state directors of student transportation concur that antiterrorism programs are vital for school bus safety. Terrorism on school buses ranks third on a list of potential U.S. targets. When you consider that there are 450,000 school buses in daily service, the ranking is not surprising (Paul 2004b).

In the aftermath of $9 / 11$, school security has much broader applications than it did when domestic violence was the extent of school and transportation security concerns. At least four high-profile hijackings have occurred in recent years in the United States. Although these hijackings were not committed by terrorists, they still showed the ease with which an unauthorized person could gain control of a school bus. Although the United States has not had an actual terrorist attack against a school bus, school buses with children on board were targeted in Israel, Thailand and Malaysia in just the past two years (Paul 2004a). 


\section{Current Solutions}

\section{Increased Tracking and Inspection of Certain Shipments}

Embedded processors, such as radio frequency identification tags, e-sensors and e-seals that are read by electronic readers at all points, are increasingly being used to track freight shipments as they make their way across the country. E-sensors can detect and document changes to a shipment that occur along its route. For example, if terrorists were to tamper with a container of hazardous waste, e-sensors would notify the proper security organization of the container intrusion (National Research Council 2003).

Other types of security devices being used to track shipments and employee activity include cryptography, the basis for most secure Web-based activities; biometric devices that identify persons on the basis of one or more physical attributes, such as a fingerprint or retina pattern; and wireless communication tracking systems that report shipment data to control points (National Research Council 2003).

\section{Employee Training}

Train operators and employees are routinely taught emergency response skills. These skills were critical to limiting casualties in the immediate aftermath of the 9/11 terrorist attacks - for instance, when Port Authority Trans-Hudson (PATH) trains helped evacuate more than 5,000 persons from the basement of the World Trade Center. Since the $9 / 11$ attacks, passenger systems have conducted further drills, testing and preparation for emergency situations. Some systems are experimenting with chemical and biological detection systems. The Washington, D.C., Metro subway system recently initiated a program for identifying suspicious packages and luggage. In addition, personnel and passengers are trained to report suspicious behavior and be ready for evacuation and emergency actions (Riley 2004).

Many transit agencies build on their existing emergency procedures to integrate steps needed in response to a terrorist attack. For example, the Houston Metro has conducted a terrorism response training exercise with the U.S. Department of Transportation involving local, state and federal emergency responders. In general, emergency plans used in the transit environment provide guidance for reporting and evaluating the incident, using the incident command system, notifying emergency response personnel or agencies, protecting personnel and equipment at the incident site, dispatching emergency response personnel and equipment to the 
site, evacuating passengers, providing briefings and information updates, managing the emergency, and restoring the system to normal (Boyd and Sullivan 2000).

\section{Inspection of Priority Tracks, Tunnels and Bridges}

Following the 9/11 attacks, bridges and tunnels into and out of New York City were heavily patrolled by police officers and the National Guard, and truck traffic was restricted. Maintenance doors on high-profile bridges, such as the Golden Gate Bridge and the Bay Bridge, were sealed shut to prevent terrorists from damaging bridge cables and anchors. In July 2002, Amtrak received a $\$ 76$ million federal grant to make New York City rail tunnels safer, including the modernizing of ventilation and communication systems and improving emergency access and other measures (Council on Foreign Relations 2004).

\section{Increased Security for Subways, Trucks and Buses}

Subways. To prepare emergency workers to handle terrorist attacks, the Washington, D.C., Metro subway system began training a select group of commuters on ways to evacuate trains and subway tunnels and help fellow passengers during a rail disaster (Layton 2004). Metro Transit Police Chief Polly L. Hanson recognizes the vulnerability of subway tunnels to explosive devices and has pointed out that the tunnels pose particular hazards during an emergency, which requires specialized training. The Metro training program includes walking the volunteer passengers into dark subway tunnels to teach them to navigate live tracks as trains roll by. "When you walk down the street, you don't have a third rail that's got 750 volts," Hanson said, referring to the high-voltage rail that powers the trains (Layton 2004).

Trucks. Although trucks haul nearly 70 percent of the nation's freight, the federal government spends significantly more on airplane safety than it does on trucking safety (Center for Strategic and International Studies 2004). However, recognizing the inherent security problems of the trucking industry and the fact that truckers are on the road 24 hours per day, the Department of Homeland Security has pledged a $\$ 19.3$ million grant to Highway Watch, a program formed in 1998 , to give truckers training in spotting terrorist activities and to provide a national hot line to report trouble. During a one-day training session, truckers learn about truck bomb terrorism around the world, how terrorist attacks play out and the ways someone might case a target. So far, about 400,000 professional truckers have been trained, with many more to go (Center for Strategic and International Studies 2004). 
There also have been security measures taken to ensure control of a truck that has been stolen or hijacked. In 2002, the U.S. Department of Transportation began a two-year project to test satellite-tracking systems with devices that can disable a truck if an unauthorized driver takes control. GPS (global positioning system) tracking also is being used by fleet operators to detect the exact location of trucks as they follow their routes and make deliveries (Wilen 2003).

Buses. Some recommendations to provide transportation safety for buses include identifying security threats and suspicious people, monitoring suspicious objects and activities, responding to a security, incident and reporting suspicions to the dispatcher.

Video cameras and GPS are two technologies that could be added to enhance bus security and help thwart terrorists. GPS allows transportation managers to know where the buses are at any given moment. In addition to using GPS to track commercial buses, Lee County Florida is thumbprinting students as they board and exit school buses so that schools know not only where each bus is, but which children are on board.

Although these technologies will be highly effective in tracking hijacked buses, they will not protect riders from other terrorist acts. For example, many buses run on gasoline, which is highly flammable. Converting buses to diesel fuel, which is more difficult to cause to explode, would be another safeguard against an attack. Unfortunately, in the case of school buses, school budgets do not stretch to cover all of these safety measures.

Training bus drivers and teachers to be prepared to implement safety plans is another measure many of our schools are trying. Modesto City (California) schools held a simulated training session for their school bus drivers, in which the adult drivers pretended to be students on a bus that was "hijacked" by "terrorists." The training was powerful because members of the County Sheriff's Department SWAT team, pretending to be the terrorists, wielded real guns (which shot blanks) and demanded to send messages. Participants said the training was frightening but also highly effective (Chrismer 1999).

\section{Future Solutions Proposed by UCF-CATSS}

It has long been recognized that the key element in prevention and proper response to security threats is operators, drivers and personnel who are well trained and prepared to act when they encounter dangerous or threatening situ- 
ations. When personnel on the scene can react and organize a proper response, situations can be resolved. UCF-CATSS was established to conduct research and to provide simulation and advanced learning technologies to enhance the performance of the transportation community.

Although traditional training practices are important, the military and the Federal Aviation Authority have learned that interactive methods that place someone in a dangerous virtual world provide realistic training in a safe environment. The simulated situation provides opportunities for trainees to consider their actions and to try out different solutions. Virtual worlds and simulation are excellent media for security training, requiring role-playing and learning technologies that are focused on the most pressing needs of the community.

\section{Awareness Education and Training}

The Federal Transit Authority has developed numerous guidelines to provide practical assistance to transit personnel and other individuals and organizations whose responsibility is to plan for, manage and recover from emergencies and disasters. Transit Watch is a campaign intended to raise the awareness of transit employees, riders and the general public. The campaign is also designed to help foster the role of transit as a safe facility in communities across the country.

The challenge to this campaign is how to raise employees' awareness without scaring them. In addition, if too much information is disseminated, employees may ignore it, especially if it is being distributed in the same way as other safety information. Identifying innovative measures for informing employees and being able to measure the utility of these measures is one of the approaches that UCF-CATSS will be implementing, using a broad multimedia approach.

\section{New Performance Technologies}

Simulation Technology. Simulation is the ultimate training technology. It allows transit agency employees to "encounter" a terrorist situation and then initiate an immediate action. Simulation technology can offer training in a realistic, virtual situation, one that mimics day-to-day transit activities and requires an immediate response to deter or mitigate a serious incident. The transit agency employee initiating the immediate response could be a bus or rail operator, station agent, or someone working in close proximity to significant numbers of patrons and other employees. However, all employees-including executive, administrative, maintenance and security employees-may find themselves in a situation where immediate action is needed. 
Knowing what to do in an emergency is critical for protecting and saving lives. Waiting for emergency response from police and fire crews may take as long as 10 to 30 minutes, depending on the type of incident. For example, in a suspected chemical attack or spill, the fire department's HAZMAT team members may take several minutes to get to the scene, put on their breathing apparatus and chemical suits, and gain access to the site. This does not mean that a transit agency employee is expected to confront a criminal or terrorist and put his or her life at risk. Instead, the employee can observe, assess and take immediate actions that reduce risks.

Computer Gaming Technology. One area in which UCF has done extensive research is the use of personal computer (PC)-based computer games as an alternative to traditional education and awareness. This is especially useful with the newer, younger employees who have grown up playing computer games. Several off-theshelf $\mathrm{PC}$ games have the potential to provide engaging, realistic information as long as proper scenarios are developed and the games are implemented appropriately. For example, gaming architecture could be adjusted to allow for user-controlled enemy combatants. Users could carry out scenarios to thwart them. City transit systems are frequent targets and users could plan surveillance and security tactics. Allowing some gamers to be "the enemy" would add innovative complexity to the games and also provide valuable information about the variety of ways an enemy might attack a target.

The military services and UCF have been looking at the use of game-based learning for over five years now. Sponsored by the Navy, the Army and the Department of Defense, UCF has developed several techniques to tailor game applications for education and training requirements.

\section{Summary}

Our community is faced with new challenges in security and, in some cases, these new challenges are almost unbelievable. Many transportation personnel cannot comprehend what happened on $9 / 11$, nor can they fathom the future attacks they may confront. The events of 9/11 seem more those of a Hollywood script than something real. Although it is not easy for people to forget such a tragedy, many return to business as usual because that is the way they choose to deal with what happened. But the world has changed. We no longer can expect "business as usual" and we must ensure that people consider events that might occur. 
Only by taking a systematic, performance-oriented approach that is relevant, credible, and engaging and that can be tailored as needed can we ensure that personnel are prepared to take immediate and appropriate action when faced with perilous situations. Much can be learned from the military and the Federal Aviation Administration's work in training their people to deal with dangerous situations and in their use of desktop computers and simulation technologies to provide training. We must use these technologies and the knowledge that has been gained to prepare intermodal transit employees and riders to deal with future potential terrorist activities. 


\section{References}

American Public Transportation Association (APTA). 2001. America under threat: Transit responds to terrorism. September 11, 2001. Passenger Transport. Special Report. http://www.apta.com/services/security/documents/911.pdf.

Boyd, A., and Sullivan, J. P. 2000. Emergency preparedness for transit terrorism. TR News. http://gulliver.trb.org/publications/trnews/trnews208_transit_security. pdf.

Center for Strategic \& International Studies. 2004. Truckers get rolling on spotting terrorism. St. Louis Post-Dispatch, September 10. http://www.csis.org/ hs/040910_slpd.htm.

Chrismer, E. 1999. Ride with terror jolts bus drivers. 2safeschools.org. Posted by permission from the Modesto (California) Bee. http://www.geocities. Heartland/ Flats/3125/fp9910.htm?200518.

Council on Foreign Relations. 2004. Ground transportation. Terrorism: Q\&A. http://cfrterrorism.org/security/ground_print.html.

Dorn, J. L. 2003. American Public Transportation Association Annual Meeting, Remarks, Salt Lake City, UT.

Hamberger, E. R. 2004. Statement before the U. S. Senate Commerce Committee Hearing on Transportation Security, March 23. http://www.globalsecurity.org/ security/library/congress/2004_h/040323-hamberger.pdf.

Kilcarr, S. 2003. NPTC's Petty: Truck terrorism threat high. Drivers Magazine. http://driversmag.com/ar/fleet_nptcs_petty_truck.

Layton, L. 2004. Metro to prepare riders for terror. Washington Post. September 2. http://www.washingtonpost.com/wp-dyn/articles/A54436-2004Sep1.html.

Mosely, B. 2002. U.S. Department of Transportation applauds Association of American Railroads' initiative to create a center to enhance security. U.S. Department of Transportation. http://www.dot.gov/affairs/dot4502.htm.

National Research Council. 2003. Cybersecurity of Freight Information Systems. Transportation Research Board Special Report 274. Washington, D.C.: National Academies Press.

Paul, B. 2004a. Security onboard. School Transportation News. http://www.stnonline.com/stn/security/stn_articles/security_onboard1.htm. 
Paul, B. 2004b. State responses on school bus security measures. School Transportation News. http://www.stnonline.com/stn/security/stn_articles/security_onboard2.htm.

Riley, J. 2004. Terrorism and Rail Security. Testimony before the Committee on Commerce, Science and Transportation, U.S. Senate, March 23.

Wilen, S. B. 2003. Countering terrorism threats: Trucking industry and multimodal distribution network vulnerabilities. Intermodal Horizons Unlimited, Inc. http://www.int/horizons.com/article-trucking.htm.

\section{About the Authors}

RONALD W. TARR (rtarr@ist.ucf.edu) is a senior research faculty member at the University of Central Florida, senior principal investigator at the Institute for Simulation and Training, program director for Simulation and Performance Technology at the Center for Advanced Transportation Simulation Systems, and program manager for Project Prime Skills. He has conducted research and workshops on distributed simulations and learning technology applications across the full spectrum of the simulation and training community. Recent projects include research and analysis of current technology approaches in adult learning, research into the utility of commercial-off-the-shelf PC-based video games for support of education, and applications of advanced performance technology to ground transportation needs.

VICKI MCGURK (vmcgurk@ist.ucf.edu) is an instructional designer with more than six years of experience in instructor-led and computer-based instruction. Ms. McGurk has most recently been involved in the design and development of the Prime Skills System to teach, assess and certify the soft skills of high school students to help them prepare for jobs.

CAROL JONES (cjones@ist.ucf.edu) is a technical writer with 20 years of experience in the computer arena, where she has designed workbooks and instruction guides for banking, credit card, education and government software systems. Ms. Jones worked for six years as a computer programmer and has taught computer science at the community college level. 